\title{
Recent Trends and Challenges on Mentoring and Virtual Coaching in IT \& ITEs Companies during Pandemic
}

\author{
Dr P. Venu Priya ${ }^{1}$, Dr L Madan Mohan ${ }^{2}$ \\ Associate Professor, AMS School of Informatics \\ ${ }^{1}$ Senior Asst. Professor, PRR College of Commerce and Management
}

\begin{abstract}
The year 2020 opened new realities as companies had to adapt to the COVID-induced new normal. As entire nations went into lockdown and businesses shut down, virtually became the go-to way of working. Even as essential services endured the field, anenormous segment of the employee population was forced to work remotely, almost overnight. Besides, organizations had to engage with these people differently, to keep them motivated in an impersonal virtual environment. Employee engagement, learning \& development, and performance management took on a new embodiment, as HR and business leaders strove to engage their people in the disruptive environment. Mentoring \&virtual coaching has been used as a useful personal development tool in this situation. Many companies apply mentoring \&virtual coaching programs as part of the employee recruiting and employee development programs. This research paper aims to examine the current positioning of mentoring \& virtual coaching programs in organizations in the IT and ITEs companies' environment. For the study, a structured questionnaire was administered to 50 participants. To analyze the advantages and disadvantages of mentoring \&virtual coaching programs in organisations, as well as the positive and negative outcomes of such development programs. To draw conclusions in the context of the analysis and will make suggestions for future improvements in the IT and ITEscompanies mentoring \&virtual coaching programs as a strategic tool for employee recruitment and employee development.
\end{abstract}

Keywords: Mentoring Process \& Types, Coaching Process \& Types, Employee Sustainability, Importance of Mentoring \& Coaching Programs in IT Companies

\section{Introduction}

Mentoring differs from coaching in that it is generally for a longer period and focuses on developing the individual holistically for the future - professionally, personally, and often, spiritually. Mentoring is often about following someone through their path in life, learning from their lessons and mistakes.

Mentoring is often a private, one-to-one relationship.

Coaching, on the other hand, may only be for a short period of time and focuses on helping the individual overcome a specific issue or performance challenge in the present. So many employees experience the power of coaching and mentoring.

While there are clear differences between coaching and mentoring, the differences complement each other, making both valuable and necessary. Together they are a powerful, unbeatable combination for developing future leaders.

\begin{tabular}{|c|c|}
\hline Mentoring & Coaching \\
\hline Life & Job related \\
\hline Relationship oriented & Job oriented \\
\hline Development Driven & Performance Driven \\
\hline Long Term & Short Term \\
\hline Requires a design Phase & Does not require design \\
\hline Strategy Development & Skills Development \\
\hline Self-selected & Come with Job \\
\hline
\end{tabular}




\section{Need of the study}

Every Organisation has own style of leadership and management. Traditional styles rely more on authoritarian and transactional styles, where a clear hierarchy and duties are spelled out. Depending on the leader, these styles can become harsh, with unrealistic expectations killing employee morale. Considered a friendly style of leadership, the mentoring and coaching style lets you build effective teams. While there always should be a clear chain of command, coaching helps foster employee skills and mentoring grooms' employees for higher level responsibilities. Organisations needed to design the learning experience while upholding the humane elements of mental health, happiness, and holistic well-being. Softer skills such as emotional resilience, mindfulness, and relearning emerged as critical future-skills. This demanded a coaching-mentoring developmental focus. During the pandemic, IT professionals took to exploring the right learning experience platform to establish virtual mentoring and virtual coaching. This need remains in post-pandemic times too.

\section{Objective of the Study}

Primary objective the study is to analyse the Recent trends and challenges of mentoring \& coaching programs in IT companies.

\section{Research Methodology}

This study was conducted among IT and ITEs employees in different companies. The sample size consists of 50 respondents namely working who were chosen based on simple random sampling technique. The study was based on both primary and secondary sources of information. Data analysis done through graphical representation.

\section{Review of Literature}

Mentoring has ancient sources, but modern-day mentoring has roots in the European apprenticeship system, when the apprentice learned skills from the master craftsman (Clutterbuck, 1985). This legacy leads to many images of 'mentoring' that reflect the difficulty of exact definition (see Carter, 2013; DfES, 2005). While coaching in an organizational sense has traditionally been viewed to correct poor performance and to link individual effectiveness with organizational performance (Ellinger et al., 2003), the difference between coaching and mentoring has not been clear.

\section{Recent trends and challenges of virtual coaching and mentoring process}

Conceptualization: IT and ITEs companies move away from the cookie-cutter approach and create a personalized and relatable learning experience for both learner and coach/mentor. The structure of coaching must be aligned with the business needs of the organization. Hence, IT companies work closely with the business and the C-suite at the concept stage to create business-relevant and engaging content.

Model: Mentoring and coaching modules must be ingrained in the virtual training platforms, by putting in place a proper process. Many IT and ITES companies have mentoring and coaching modules as a part of their eLearning solutions.

Induction: Any learning intervention requires an extensive change management process for people to adopt and embrace it. Before directly implementing the mentoring and coaching companies must orient stakeholders to the new process through extensive education.

Implementation: Technical implementation should be such that the tool provides a glitch-free and continuous user-experience because a great employee experience is essential to ensure the adoption of mentoring-coaching as a way of life.

Assessment: It is important to track learning progress through qualitative inputs and metrics. According to the Kirkpatrick model, IT companies must try to achieveBehaviour stage and Results stage but in the emerging stages, it is also important to track operational metrics such as completion rates. Seeking qualitative feedback also goes a long way in gaining useful behavioral insights and enabling continuous improvement in the process.

\section{Mentoring Process}

Successful mentoring relationships go through four phases: Initiation Phase (preparation), Cultivation Phase(negotiating), Separation Phase (enabling growth), and Redefinition Phase(closure). These chronological phases build on each other and vary in length. In each phase, there are certain steps and strategies that lead to mentoring brilliance. 


\section{Mentoring Process}

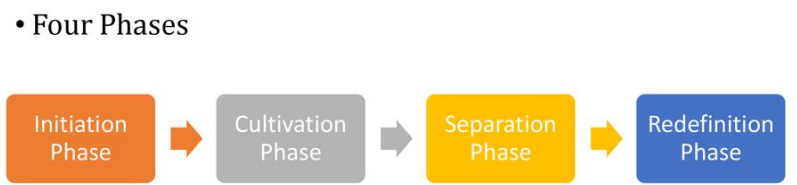

\section{Types of Mentoring:}

Traditional One-on-one Mentoring: A mentee and mentor are matched, either through a program or on their own. Mentee-mentor associates participate in a mentoring relationship with structure and timeframe of their making or as determined by a formal mentoring program.

Distance Mentoring: A mentoring association in which the two parties (or group) are in different locations. Sometimes called "virtual" mentoring.

Group Mentoring: A single mentor is matched with a cohort of mentees. Initial program structure is provided while allowing mentor to direct progress, speed, and activities.

Coaching Process: Coaching is a two-way communication process that involves that the supervisor and the employee both be fully engaged and motivated. Set specific measurable goals, agree on next steps in terms of actions and planning, and gain a commitment. Follow the employee's make progress.

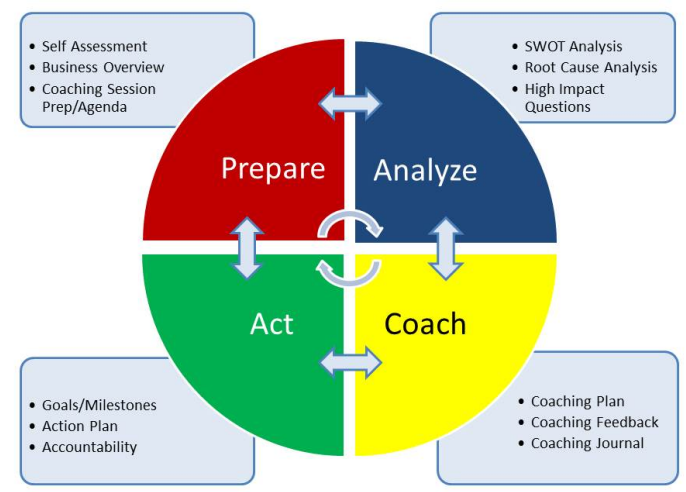

\section{Types of Coaching:}

Humanist coaching: It has everything to do with helping leaders reach their full potential. The term self-actualization is all about. It relies heavily on the relationship established between employee and leader ultimately create the success of the employee.

Mature development coaching: It focuses on the different stages of adult development in employee. This means that the coach is working to figure out where the employees is in their development and helps the employee to move toward more mature understanding of authority and responsibility and greater tolerance for ambiguity.

Cognitive coaching: It is centered around a model that supports individuals and organizations in becoming self-directed, and in turn, become self-managing, self-monitoring and self-modifying. The results are stronger individuals within a team and better organizational teams overall.

Positive psychology coaching: It is often seen as a strengths-based coaching. The thought here is that the coach would help the employee expand existing strengths to build positive emotions, creating greater happiness and increasing higher levels of performance.

\section{Systemic Coaching}

To accomplish such high measurable performance levels and relatively immediate results, systemic coaches are intensely trained to develop their perceptual and communication skills. 
Goal-oriented coaching: It is probably the type of coaching in the workplace many of us are most familiar with. It is helping employees regulate and direct their interpersonal and personal resources to better attain one or more goals.

Adaptive coaching: It is profoundly goal oriented in nature. It is incorporating the best aspects of coaching like systemic, positive, and even cognitive. It balances the personal and practical needs of the employees.

\section{Employee sustainability at workplace}

Companies that focus on employee sustainability procedures can resolve the anxiety people feel between their personal values and their work by providing a superior purpose.

- Enables employees to latch onto that higher purpose and use the company to express their values, which in turn, creates meaning in and at work.

- Truly sustainable business is profitable business, and it helps the cause to contribute to this knowledge with employees.

- To strengthen the 'can do' belief among employees, it is important to invest in educating employees about sustainability as well as to create systems and processes that make it simpler for them to integrate sustainability into their business decisions.

- Create every employee a sustainability champion.

- Co-create sustainable practices with employees. A great way to entrench sustainability in a company is to act on employee initiatives.

- $\quad$ Encourage wholesome competition among employees.

- To keep visibility high and reinforce the idea that achievements in sustainability are significant for the company, it is also important to celebrate success when goals are reached, or awards won

- Showcase the superior purpose by creating transformational change.

\section{Mentoring \& Coaching in IT Organizations}

IT Organizations implement Mentoring and Coaching programs to align the goals of the company with the professional development of its employee. For example, the mentoring program can target new employees in product development when the goal of the organization is to bring innovative products to the market. Developing employees in weak areas of the company can also benefit the business's organizational goals.

Companies can benefit extremely when they deploy all or any of the following methods to mentor and coach its employees:

$>$ Companies can assign a mentor or coach to new employees during the initial period of settling down in an organization to help them get used to the culture of the company as well as bring them up-to speed on company procedures and policies. Mentoring also provides the worker with a leader he can turn to with questions. The coach can provide the new employee with information on the corporate culture, organizational structure and procedures that will help the younger professional settle into his role in the business.

$>$ Employee Growth and Development is accomplished by providing the individual who is mentored or coached with practical knowledge that bridge the gap between educational theory and actual business practices.

$>$ Mentoring generally helps boost employee morale and commitment, experts say. From increased self-esteem to increased organizational productivity and career development, the benefits of an organization that actively supports mentoring are abundant.

$>$ Reduced employee turnover boosts productivity in an organization. High employee turnover costs organizations money in the form of recruitment hiring and training of replacements. Companies should weigh the costs of implementing a Mentoring\& Coaching program against the inflated cost of employee turnover to establish the benefits of coaching and mentoring.

$>$ Team efficiency can be developed by Mentoring\& Coaching. The process enables managers to identify the strengths and weaknesses of each employee. This allows the organization to take advantage of on the resources at hand to keep the whole team working efficiently

$>\quad$ leaders' roles do not end with implementing coaching and mentoring processes and tools. In fact, this is just the beginning. Coaching and mentoring success requires a 'growth' and 'developmental' mindset across employees, and this, in turn, demands an extensive change management exercise.

$>\quad$ The impact of coaching and mentoring is not limited to mere leadership development training but extends to broader agendas such as employee engagement and wellbeing. Due to the decentralization of leadership, coaching-mentoring finds value across hierarchies and is a powerful tool for organization-wide people-transformation. 


\section{Data Analysis \& Interpretation:}

Gender:

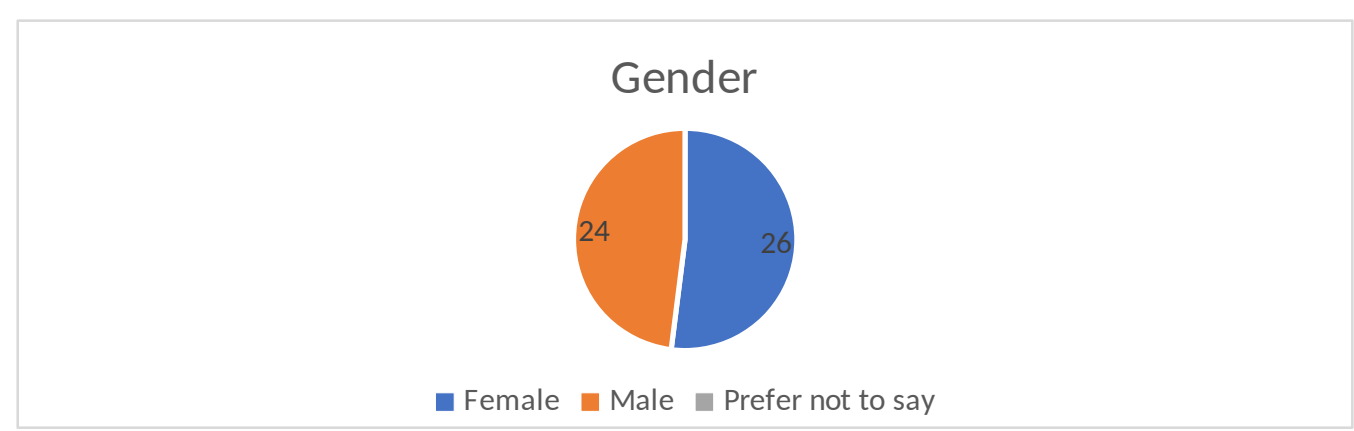

1. Due to impact of the recent pandemic on the workplace, is your organization relying more on remote/virtual coaching and mentoring?

\section{Impact of Recent Pandemic}

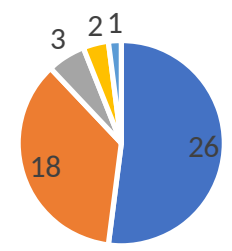

Yes, to some level

Yes, to a large level No

No, but we probably will Maybe we plan in future

2. Does your organization provide formal training like Virtual coaching and mentoring programs?

\section{Organisation providing Formal training}

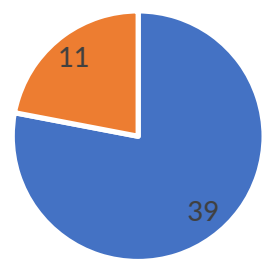

a Yes No

3. Who does the virtual coaching and mentoring in your organization?

\section{About Coaches and Mentors}

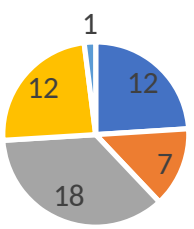


4. Your organization contains the following culture-related factors in mentoring and coaching

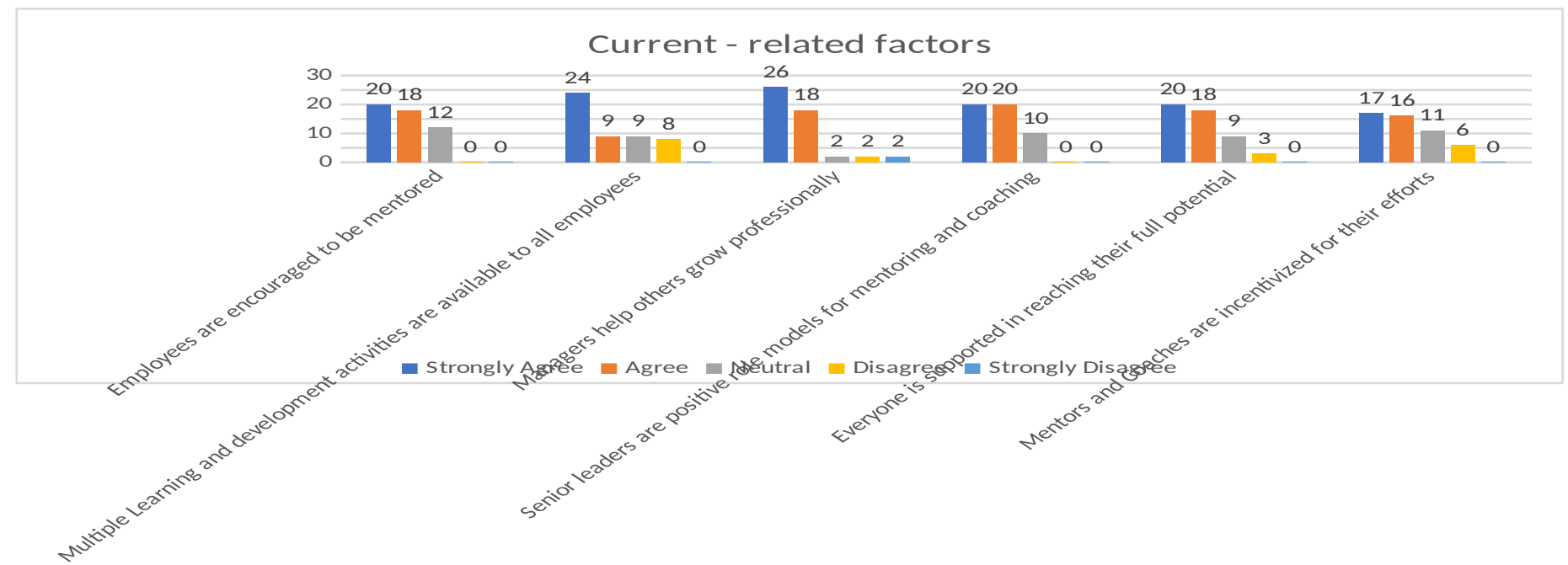

5. Below online challenges currently hinder Virtual coaching and mentoring in your organization?

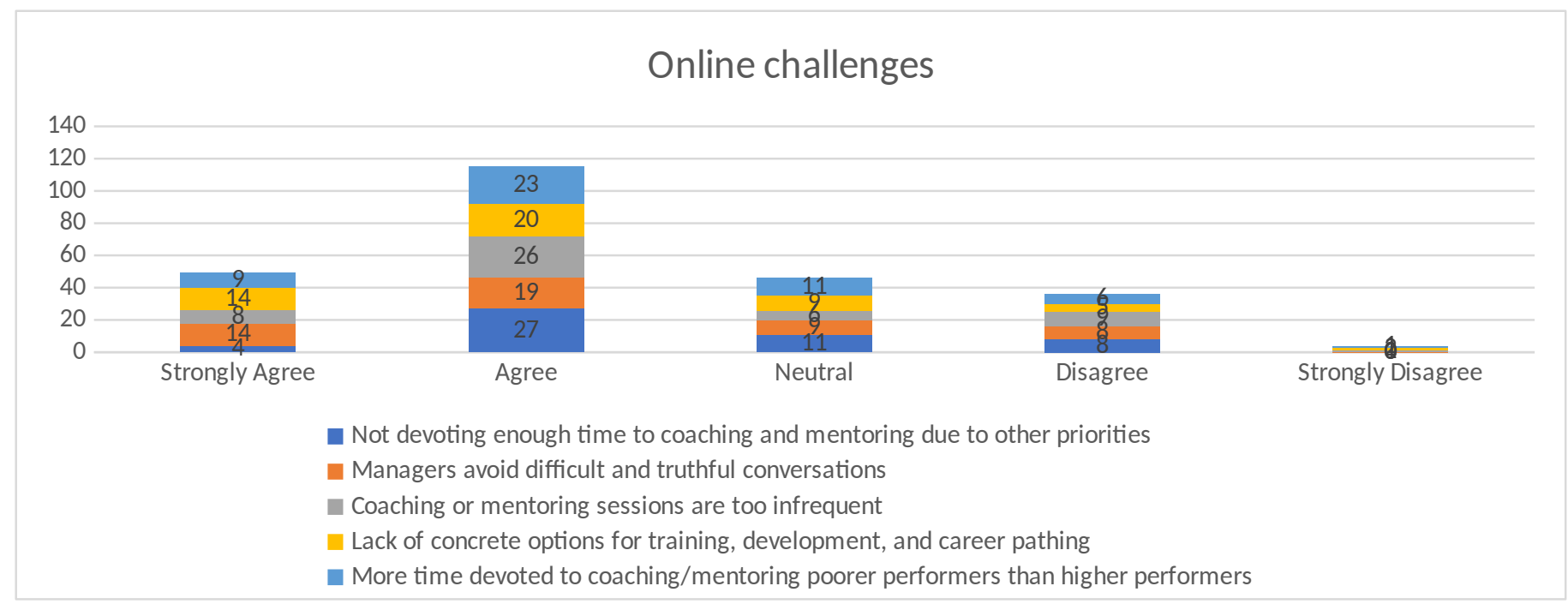

6. Reasons for using virtual coaching and mentoring programs in your organization

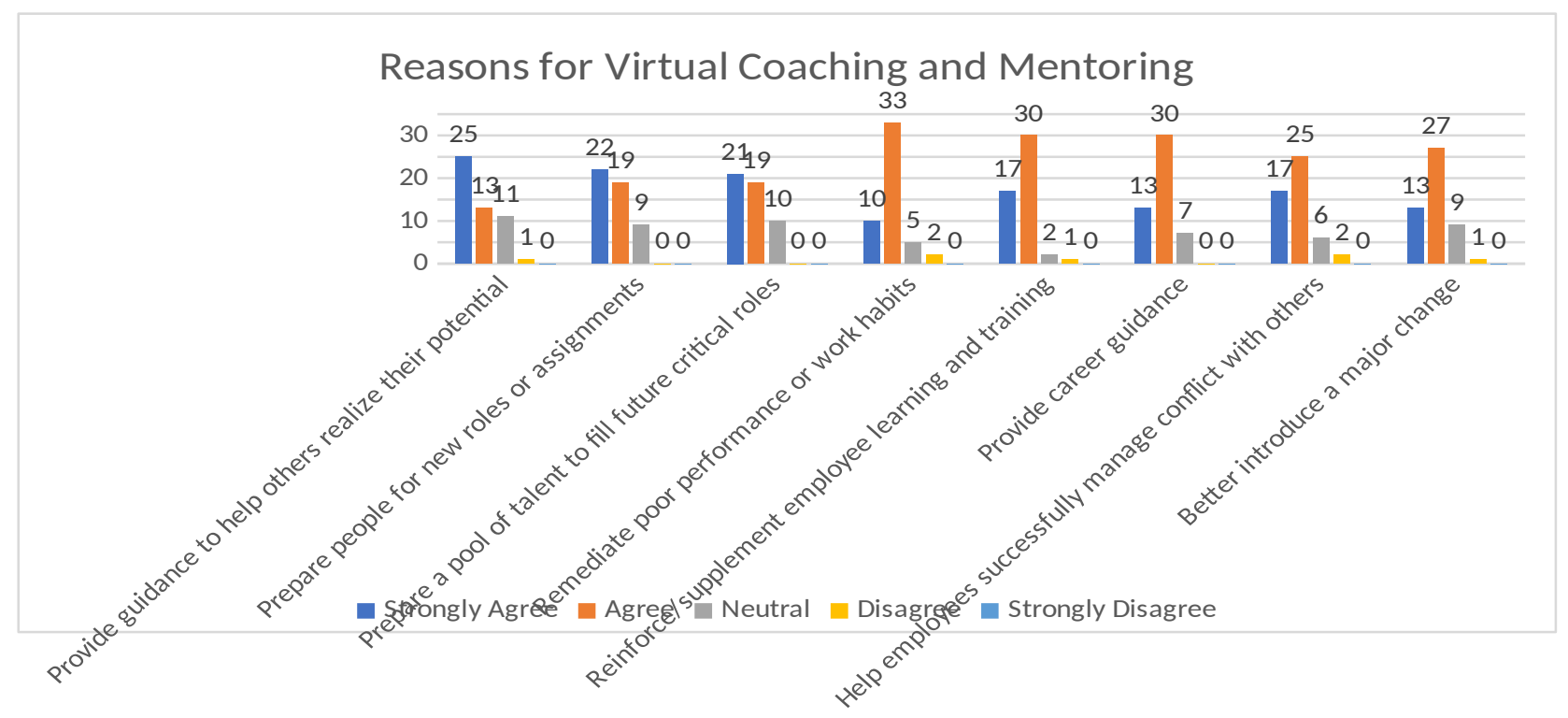


7. Relationship Type - When you think about communicating with your Mentor, how do you envision the relationship?

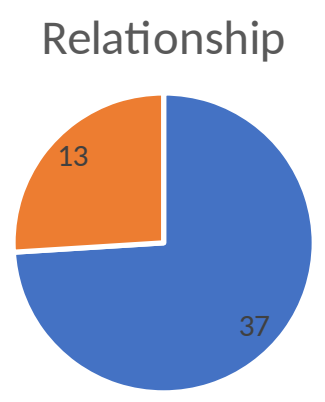

More casual - we will contact each other when we want to talk, knowing that the other person will be available for me when needed.

More structured - set schedule

8. Can continued organizational learning give you better ROI than traditional employee training?

\section{Modern Vs Traditional Learning}

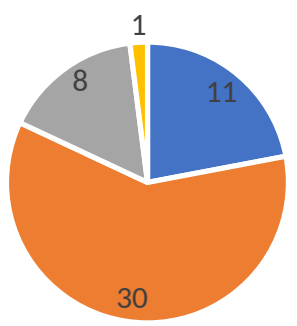

Strongly Agree $\square$ Agree $\square$ Neutral Disagree $\square$ Strongly Disagree

9. Does Participating in coaching helps you to meet your staff development needs?

\section{Staff Development Needs}

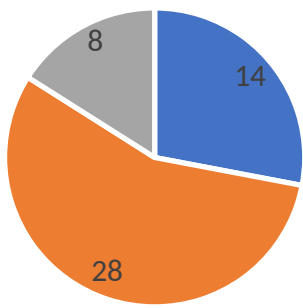

Strongly Agree $\square$ Agree $\square$ Neutral $\square$ Disagree $\square$ Strongly Disagree

10. Does your organization conducting coaching sessions are meeting your expectations?

\section{Meeting Expectations}

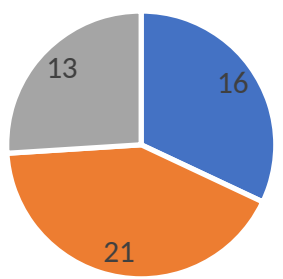


11. Does your Virtual Coaching and mentoring programs conducting Real-time, timely and objective feedback and performance analysis?

\section{Performance analysis

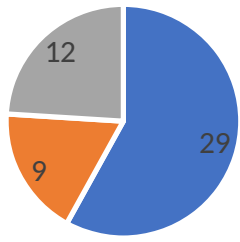 \\ - yes No May be some times}

12. Which channel is comfortable to attend learning and development sessions

\section{Channels}

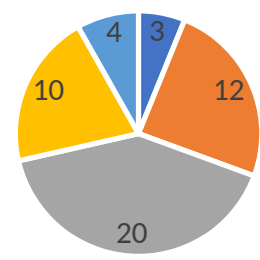

- Blended Digital(web + Mobile) platforms c Classroom

Virtual $\square$ Self Paced

\section{Findings}

Most of the employees say that yes, to some level organization is relying on virtual coaching and mentoring.

$>$ Most of the respondents say yes that the organization are providing virtual coaching and mentoring

$>$ According to the responses we can say that employees mostly get the mentoring or virtual coaching from their colleagues, executives, and at times by direct supervisors.

$>\quad$ Most of the employees agree that the employees are encouraged to be mentored and they will help for multiple learning and development activities. Respondents strongly agree that Mentors and coaches were incentivized their efforts.

$>\quad$ As per the analysis we can say that most of the employees agree that they are not devoting enough time to coaching and mentoring due to other priorities.

$>$ Among the respondents most of them say that the relationship will be more casual so that they can contact each other knowing that the other person will be available for me when needed.

$>\quad$ Mentoring and coaching help managers to grow professionally and develop many activities and to work with positive aspect by putting their best efforts in the Organization.

$>\quad$ Most of the people agree that the organizational learning will give you better ROI than traditional employee training.

$>$ Most of them agree that coaching will help the employees to meet staff development needs.

$>\quad$ Most of the respondents agree that they the organizations are meeting their expectations

$>\quad$ Maximum number of respondents say yes that they have timely feedback about their performance analysis

$>$ Maximum of the respondents said that they feel comfortable to attend blended learning and development sessions

\section{Conclusion}

The study has analyzed that mentor and coach is the bridge between individual and organizational needs. They help employees find their purpose and develop their skills. If an employee receives personal and professional development at work, they're more likely to be satisfied with their job, which fosters greater employee engagement and retention. Employees aren't the only ones benefitting from the program mentors and coaches can gain just as much. In this pandemic Mentoring\& virtual Coaching can provide an assortment of benefits for IT and ITEs organizations. When conducted in an effective and beneficial manner, Mentoring\& Coachingprovides employees a way to connect, learn and grow within the company and along their own career paths. Mentoring\& Coachingserve as learning tools in the job work that can lead to empowering employees both professional and personal life. The employees who are coached and mentored often receive the greatest benefit, but the coach or mentor also benefits and may feel a sense of empowerment from the relationship. Employees change their perceived skills, and they are understanding the reality and practical outcomes of this type of learning and development strategy helps one evaluate the need for a Mentoring\& Coaching program in their IT and ITEs organization. 


\section{References}

[1] Barton, K. (2001). Connecting with success: How to build a mentoring network to fast-forward your career. Palo Alto, CA: Davies-Black.

[2] Cravens, L. (2003). Online mentoring: Programs and suggested practices as of February, 2001. Journal of Technology in Human Services, 21 (1/2), 85-109.

[3] Fulop, M. (2002). Assessing the potential of e-mentoring: A survey of current issues. Portland, OR: National Mentoring Center, Northwest Regional Educational Laboratory

[4] Gender Sensitisation of Tertiary Institutions. The Role of Human Resource Development and Managemente ${ }^{3}$ Association for the Development of Education in Africa (ADEA), Toolkit Module 3, pdf, 2006

[5] Human Resources Development and the United Nations $\boldsymbol{Z}^{\boldsymbol{T}}$ pdf, 1995

[6] Headlam-Wells, J. (2004). E-mentoring for aspiring women managers. Women in Management Review, 19 (4). $212-218$.

[7] Kimball, I. \& Eunice, A. (1999, November). Zen and the art of facilitating virtual learning communities. Los Angeles, CA: Paper presented at the Thinkquest Teachers Summit

[8] Muller, C. B. (2000). Mentornet. AWIS Magazine 24 (1), 19-23.

[9] SCHOOLEY, C., "Drive Employee Talent Development Through Business Mentoring Programs", Business Process Professionals, 2010

[10] SHERMAN, A. Raising Capital: Get The Money You Need To Grow Your Business, 2nd Edition., Saranac Lake, NY, USA: AMACOM, 2005. p 83.

[11] Single, P. B. \& Single, R. M. (2005). E-mentoring for social equity: Review of research to inform program development. Mentoring and Tutoring, 13 (2), 301-320.

[12] Wenger, E., McDermott, R., \& Snyder, W. (2002). Cultivating communities of practice. Boston, MA: Harvard Business School Press 